\title{
Changes of Root Hydraulic Conductivity and Root/Shoot Ratio of Durum Wheat and Barley in Relation to Nitrogen Availability and Mercury Exposure
}

\author{
Celestino Ruggiero*, Giovanna Angelino \\ Dipartimento di Ingegneria Agraria e Agronomia del Territorio, Università di Napoli 'Federico II' \\ Via Università 100, 80055 Portici, Italy
}

Received: 7 March 2006. Accepted: 26 September 2006

\begin{abstract}
Summary
The aim of this research was to verify, on whole plant level and during all the plant cycle, the hypothesis that nitrogen deficiency reduces root hydraulic conductivity through the water channels (aquaporins) activity, and that the plant reacts by changing root/shoot ratio. Root hydraulic conductivity, plant growth, root/shoot ratio and plant water status were assessed for durum wheat (Triticum durum Desf.) and barley (Hordeum vulgare L.), as influenced by nitrogen availability and $\mathrm{HgCl}_{2}$ treatment. On both species during the plant cycle, nitrogen deficiency induced lower root hydraulic conductivity (-49 and $-66 \%$ respectively for barley and wheat) and lower plant growth. On wheat was also observed cycle delay, lower plant nitrogen content, but not lower leaf turgor pressure and epidermic cell dimension. The lower plant growth was due to lower plant dimension and lower tillering. Root /shoot ratio was always higher for nitrogen stressed plants, whether on dry matter or on surface basis. This was due to lower effect of nitrogen stress on root growth than on shoot growth. On wheat $\mathrm{HgCl}_{2}$ treatment determined lower plant growth, and more than nitrogen stress, cycle delay and higher root/shoot ratio. The mercury, also, induced leaf rolling, lower turgor pressure, lower NAR, higher root cell wall lignification and lower epidermic cell number per surface unity. In nitrogen fertilized plants root hydraulic conductivity was always reduced by $\mathrm{HgCl}_{2}$ treatment (-61 and $38 \%$, respectively for wheat and barley), but in nitrogen unfertilized plants this effect was observed only during the first plant stages. This effect was higher during shooting and caryopsis formation, lower during tillering. It is concluded that barley and durum wheat react to nitrogen deficiency and $\mathrm{HgCl}_{2}$ treatment by increasing the root/shoot ratio, to compensate water stress due to lower water root conductivity probably induced by lower aquaporin synthesis or inactivation. However, this compensation is not enough to keep a normal water status and this leads to lower plant growth. At the same time some doubts persist about mercury toxicity on other plant functions besides the aquaporin blockage.
\end{abstract}

Key-words: aquaporins, nitrogen, root hydraulic conductivity, mercury, root/shoot ratio.

\section{Introduction}

The plant capacity to compensate water losses through transpiration stream is in relation to shoot/root ratio and root hydraulic conductivity. This ratio may changes in relation to many factors. Shoot/root decreases with ageing (Brouwer, 1968; Troughton, 1978), changes with environmental conditions (Brouwer, 1962b; Troughton, 1977b; Schulze, 1982), and it is lower with nitrogen deficiency. Usually, this last decrease is explained as a functional equilibrium between shoot and root (Brouwer, 1962b) and it is considered a plant strategy to improve nitrate uptake, when nitrate concentration in the soil is low. However, this point of view was questioned, because, considering the high nitrate mobility, the plant may compensate low concentration by a higher uptake (Robinson, 1996). By side, some researches showed that root water conductivity is influenced by nitrogen, phosphorus and sulphur availability (Radin and Ackerson, 1981; Radin and Edebock, 1984). On cotton nitrogen deficiency caused a $60-85 \%$ reduction of root conductivity (Radin and Matthews, 1989). Similar effects were shown on tomato

* Corresponding Author: Tel.: +39 081 2539124; Fax: +39 081 7755129. E-mail address: cruggier@unina.it. 
and barley, with lower stomatal conductance and photosynthesis (Chapin et al., 1988; Gilbert et al., 1997). On wheat nitrogen deprivation induced reduction of root conductivity and the amplitude of its diurnal cycle. Furthermore, nitrogen deprived plants were insensible to $\mathrm{HgCl}_{2}$ exposure (Carvajal et al., 1996). In this occasion, the lack of mercurial sensitivity may suggest a lack of PIP1 type water channels, which are $\mathrm{Hg}$ sensitive (Clarkson et al., 2000). Transgenic Arabidopsis plants, which expressed an antisense copy of PIP1b, showed a lower expression of different PIP1 homologous. These plants showed a higher root/shoot ratio (Kaldenhoff et al., 1998). Also on Lotus japonicus, with nitrogen deficiency (Henzler et al., 1999) was observed a lower root conductivity and transpiration. At the same time it has been noticed an AtPIP1 and AtPIP2 transcription decrease, with quantitative variations during the day. To explain these phenomena was proposed the hypothesis that with nitrogen deficiency aquaporin synthesis is reduced. The low aquaporins content then explain the low root conductivity and the reduction of the amplitude of diurnal cycle. To compensate the low root conductivity the plant reacts with a higher root/shoot ratio (Clarkson et al., 2000). Potassium and sulphur, which have some importance for plant water balance, deficiency did not change root /shoot ratio (Karmoker et al., 1991; Smith et al., 1998).

However, this hypothesis allows to some dubiousness. The functional link between molecular and whole plant is far from being full understood. The effects of these changes on plant growth at whole plant level are unknown, particularly the reduction of root conductivity. Most of these researches have been carried out with treatment applied for short time, on excised root, or cells, anyone for all the plant cycle. The most dubiousness is for plant grown in the field, where there are many factors involved and interacting between themselves. At the same time the effects on plant growth to continuous aquaporine blockage (i.e. $\mathrm{HgCl}_{2}$ exposure) are still unknown.

Fertilization and particularly nitrogen fertilization is one of the most important factors controlling yield. Consequently, a deeper knowledge of nitrogen physiology has a high importance both theoretically and practically, particularly if it has interference on root water uptake, an other factor which has high influence on yield (Vandeleur et al., 2005).

The aim of this research is to verify, on whole plant level and during all the plant cycle, the hypothesis that nitrogen deficiency reduces root hydraulic conductivity through the water channels (aquaporins), and that the plant reacts by changing root/shoot ratio.

On nitrogen fertilized and unfertilized barley and durum wheat plants were evaluated: root water hydraulic conductivity, the effects of mercuric chloride $\left(\mathrm{HgCl}_{2}\right)$ treatment on this parameter and root/shoot ratio. On fertilized and unfertilized with nitrogen wheat plants, subject or not to continuous $\mathrm{HgCl}_{2}$ exposure, the whole plant growth and plant water status was, also, monitored from tillering to wax ripening.

\section{Materials and methods}

The research was carried out during 2002-2005, in Portici (South Italy). Ten caryopsis of barley (Hordeum vulgare L. cv. Roma) have been sown on December 20, 2002, on plastic cylinder $(0.15$ $\mathrm{m}$ of diameter and $1.0 \mathrm{~m}$ deep) filled with a $\mathrm{P}_{2} \mathrm{O}_{5}$ and $\mathrm{K}_{2} \mathrm{O}$ fertilized clay loam soil. After emergency only five plants were grown in each container, placed in a trench in open field. At the beginning of tillering half containers were fertilized with ammonium nitrate, the others were kept without nitrogen fertilization. At the end of tillering, at shooting, at earing and at wax ripening, six cylinder for each thesis (fertilized and unfertilized whit nitrogen) have been selected and three have been irrigated with a $\mathrm{Hg}$ $\mathrm{Cl}_{2}$ solution $(50 \mu M)$, until saturation, the others were irrigated with the same volume of normal water. The containers were left to drain and then the bottom and the top were wrapped with a plastic film. The day after data for root water conductivity, shoot and root growth were collected following Ruggiero et al. (2003).

Concerning wheat root conductivity, the plants were grown on $14 l$ pots, filled with a sandy soil. The soil was fertilized as the barley and five caryopsis of durum wheat (Triticum durum Desf., cv Simeto) were sown on December 12. After establishment, only one seedling was grown in each pot, fertilized with the same technique used for barley. The observations on root hydraulic conductivity were done on April 8 and 
22, May 7, 21 and 31, from the beginning of shooting to milk ripening. For each data, four pots for each thesis (fertilized and non-fertilized with nitrogen) were selected and two of these were irrigated with an $\mathrm{HgCl}_{2}$ solution as for barley, while the others were irrigated only with normal water. All tillers were cut two days before to allow cicatrization, and then closed with clamps. The main stem was cut above the soil line, and the entire intact root system was placed in a pressure chamber with the cut stump exposed. The shoot was collected to evaluate leaf area and shoot dry weight and root water conductivity was evaluated, following the technique as reported by Rúdinger et al. (1994). Subsequently, the pots were opened to collect soil samples for soil moisture and root analysis, as for barley.

On December 6, 2004, six caryopsis, of the same durum wheat cultivar grown the previous year, were sown on plastic cylinders of the same type used for barley. The containers were filled with a calcareous sand ground and placed in open field as for barley. After establishment, two seedlings were grown in each container. Also in this case, four theses were compared: ferilized and un-fertilized with nitrogen, and treated and un-treated with $\mathrm{HgCl}_{2}$ for all the plant cycle. A half strength Hoagland nutrient solution for macro and micronutrient was used, with or without nitrogen. For the treated plants $\mathrm{Hg}$ $\mathrm{Cl}_{2}$ was added to obtain a $50 \mu M$ concentration. To avoid mercury accumulation, the containers have been exposed to rainfall and the volume solution used for daily irrigation was in excess. From the beginning of tillering to wax ripening and precisely on March 17 and 30, April 12 and 21 , May 3, 17, and 30 and June 11, on three containers (6 plants) for each thesis shoot and root growth was monitored. On April 12, 19 and 26, on May 3,17 and 30, the plant water status was, also, evaluated. On April 12 and May 17, epidermic leaf cell number and size and plant nitrogen content were evaluated. On root system, dry matter, number of main roots, root diameter for main and secondary lateral roots and total length were measured. On May 17 , for $\mathrm{Hg}$ $\mathrm{Cl}_{2}$ treated and untreated plants, total root cell wall was analyzed following the van Soest's method (1971). This analysis had 6 replications and was done on total root system, mixing the fertilized and unfertilized plants. Root length was measured by the Newman's method (1966) on dry root samples after cutting in $1 \mathrm{~cm}$ pieces. Root diameter and area were obtained as before. Roots separation from the sand ground was made shaking gently at first, to separate the larger material, and then washing, decanting and filtering on sieve $\left(0.04 \mathrm{~mm}^{2}\right.$ pore size $)$. On shoot, dry matter, separately for leaf, stem and ear, leaf area, and leaf, stem and ear number was evaluated. Plant water status was monitored following Ruggiero et al. (1991). The anatomic analysis was done on two leaves of three plants for each thesis. Leaf epidermic tissue (length 0.5 $\mathrm{cm}$ ) was obtained through crushing of leaf with exclusion of green material and rising of the tissue by adhesive tape. They were dyed with toluidine blue, washed with distilled water and mounted with a water and glycerine solution. On these samples cells number on four zones of known area were counted, while the dimension was obtained by dividing the known leaf area and cells number. Nitrogen content of root, shoot and caryopsis, was evaluated on dry matter by the Kjeldal method.

All the data were subjected to ANOVA, after transformation when necessary, and the means were separated by the Duncan's test.

\section{Results}

\subsection{Barley}

Fertilized plants showed the maximum leaf area value at the end of shooting (Fig. 1); while for unfertilized plants this was observed at earing, when also root area showed the maximum val-

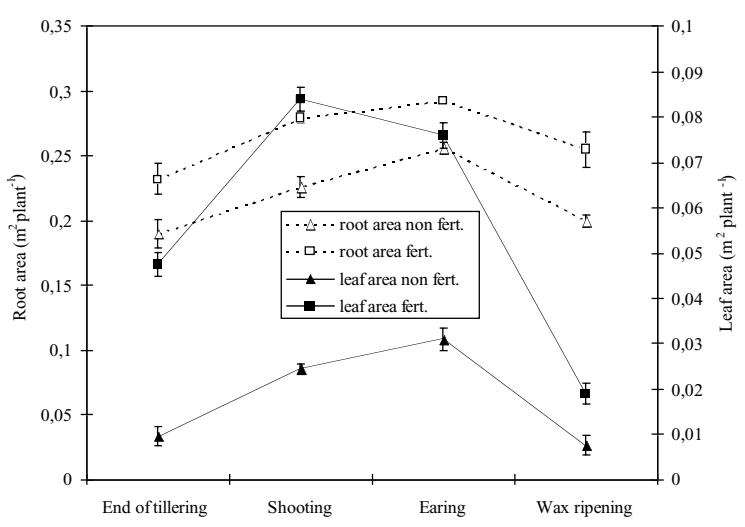

Figure 1. Root and leaf area values for the four thesis of barley during the growing cycle. Average $\pm \mathrm{SE}$. 
ue. Root system of fertilized plants, on the contrary, grew until the end of tillering and then decreased. The nitrogen deficiency reduced plant growth, but mainly shoot growth, with a higher root area/leaf area ratio for unfertilized plants. The differences of root area where due to root length, while secondary lateral root diameter was not influenced by nitrogen deficiency, with a mean value of $0.2 \mathrm{~mm}$.

For fertilized and untreated plants, root conductivity (Fig. 2) increased during shooting, and then decreased. As average, plants subjected to $\mathrm{N}$ deficiency showed a $50 \%$ reduction of root conductivity, but with different reduction values during the plant cycle. At the end of tillering this reduction was $31 \%$, during shooting was $70 \%$, in the later phenological stages was around $45 \%$. Also $\mathrm{HgCl}_{2}$ exposure reduced root conductivity, but less than $\mathrm{N}$ deficiency, with a mean value of $37 \%$, more at wax ripening $(60 \%)$, less during the other part of the cycle. This only for fertilized plants, while for unfertilized plants the $\mathrm{HgCl}_{2}$ treatment effect was clear only in the first observation (end of tillering), later it was practically absent.

\subsection{Wheat 2004}

For unfertilized plants shoot dry matter accumulation was very low (6.9 vs $31.1 \mathrm{~g}$ per plant), with tillers almost absent. Also root growth was reduced by $\mathrm{N}$ deficiency, with a mean root area of $0.2 \mathrm{~m}^{2}$, while for fertilized plants this value was $0.4 \mathrm{~m}^{2}$. Mean root/shoot ratio, on surface

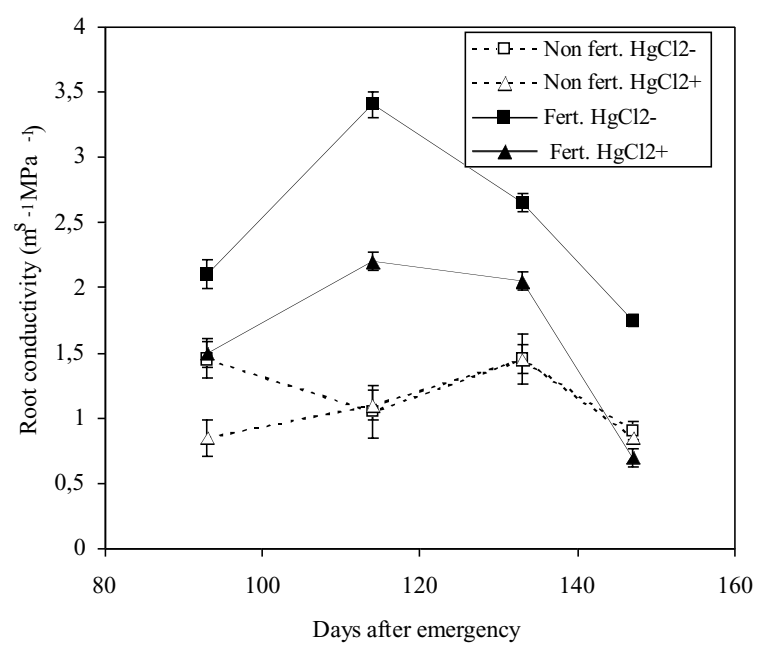

Figure 2. Mean value of root water conductivity for the four thesis of barley during the growing cycle. Average \pm SE. basis, was higher for unfertilized (10.7) than for fertilized plants (5.5). As for barley, the different root area values were determinate by root length.

For the fertilized and untreated plants root hydraulic conductivity was higher than for other plants, particularly until flowering (Fig. 3), and was increasing from the end of tillering to shooting, decreasing until the beginning of caryopsis formation and constant later. For the other plants the initial increasing was not evident and the decreasing was shown only until flowering. Nitrogen deficiency induced, as average, a $66 \%$ reduction of root hydraulic conductivity, more in the first part of the plant cycle, less after. Mercuric chloride treatment, reduced root hydraulic conductivity, but mainly that of the fertilized plants $(61 \%)$. For the unfertilized plants the effect of $\mathrm{HgCl}_{2}$ treatment was low and was shown only at the beginning of plant cycle, later was, practically, absent.

\subsection{Wheat 2005}

Nitrogen deficiency and $\mathrm{HgCl}_{2}$ treatment strongly reduced plant growth (Fig. 4), particularly the second one, which induced a $90 \%$ growth reduction, while by $\mathrm{N}$ deficiency this reduction was $78 \%$. These effects were already observed at the beginning of plant cycle, with a high remark during shooting and earing. After flowering the nitrogen stressed and $\mathrm{HgCl}_{2}$ treated plants showed a growth recovery. Growth differences were due as to lower plant dimen-

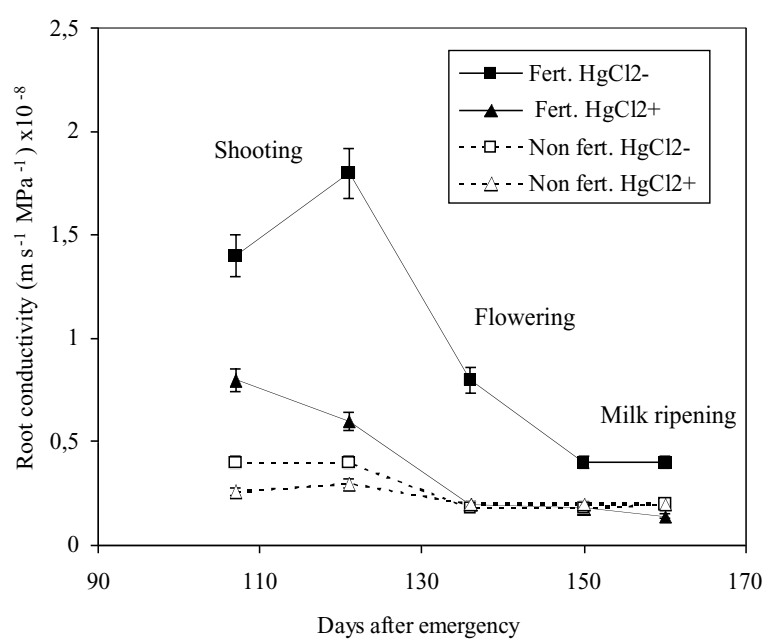

Figure 3. Mean value of root water conductivity for the four thesis of wheat during the 2004 growing cycle. Average \pm SE. 


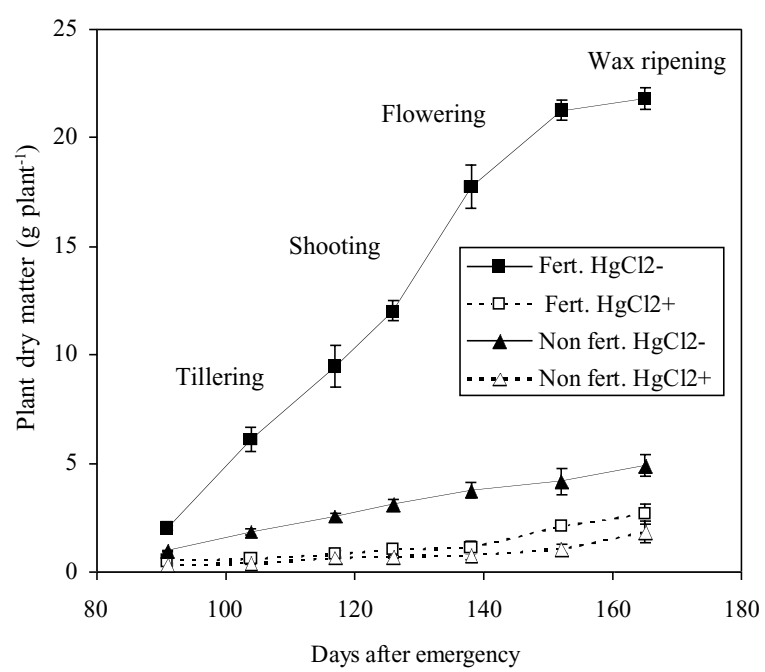

Figure 4. Mean value of plant dry matter for the four theses of wheat plants during the 2005 growing cycle. Average $\pm \mathrm{SE}$.

sion as to lower tillering (Tab. 1). Both stresses induced a 10-20 days delay of plant cycle, more for $\mathrm{HgCl}_{2}$ treated plants.

The plant growth reduction by $\mathrm{N}$ deficiency and $\mathrm{HgCl}_{2}$ treatment regarded as shoot as roots (Tab. 1), but was lower for roots with a different root/shoot ratio for the four theses (Fig. 5). Nitrogen deficiency and $\mathrm{HgCl}_{2}$ exposure increased root/shoot ratio, particularly $\mathrm{HgCl}_{2}$ exposure. The highest root/shoot ratio was observed for the unfertilized and treated plants, but only until shooting, while after both the $\mathrm{HgCl}_{2}$ treated plants showed the same root/shoot ratio. After flowering for all theses the root dry matter percentage was almost the same. Nitrogen deficiency and $\mathrm{Hg}$ $\mathrm{Cl}_{2}$ treatment influenced, also, root area/leaf area

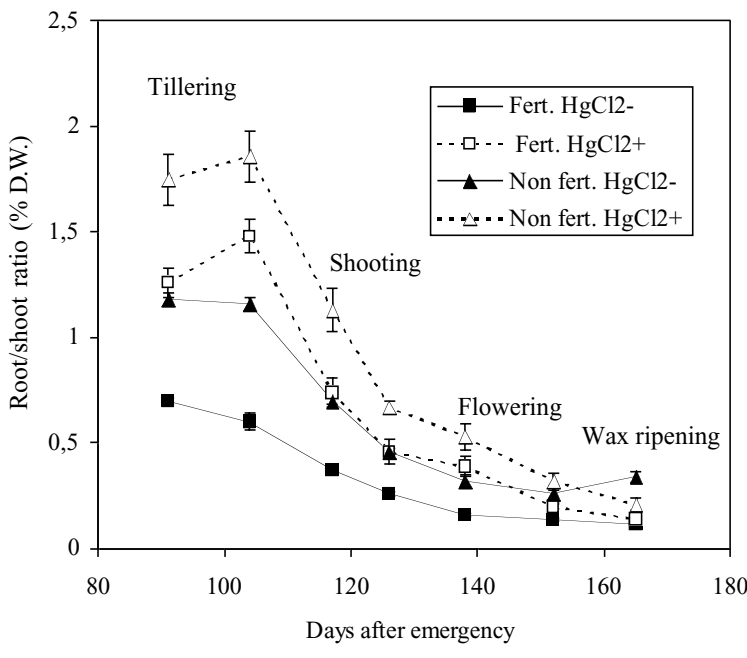

Figure 5. Mean value of root/shoot ratio on dry matter basis for the four theses of wheat plants during the 2005 growing cycle. Average \pm SE.

ratio (Fig. 6). The nitrogen fertilized and untreated plants presented the lower value of this ratio. The treated plants until earing showed a similar value, after for the unfertilized and treated plants was monitored the higher value. Also the trend was different for the four theses: the unfertilized and treated plants after earing showed a constant ratio, for the other plants this ratio was increasing until earing and then decreasing.

The different root area/shoot area ratio was determined mainly by root length per plant (Tab. 1), the secondary lateral root diameter had small changes, with a $0.2 \mathrm{~mm}$ mean value, while the main roots showed differences among the four theses (Tab. 1). The largest root diameters were measured for the fertilized and untreated

Table 1. Plant parameters measured on wheat during 2005.

\begin{tabular}{|c|c|c|c|c|}
\hline & $\begin{array}{l}\text { Fertilized } \\
\mathrm{HgCl}_{2}^{-}\end{array}$ & $\begin{array}{c}\text { Fertilized } \\
\mathrm{HgCl}_{2}+\end{array}$ & $\begin{array}{c}\text { Unfertilized } \\
\mathrm{HgCl}_{2}-\end{array}$ & $\begin{array}{c}\text { Unfertilized } \\
\mathrm{HgCl} 2+\end{array}$ \\
\hline Root length (m plant $\left.{ }^{-1}\right)$ & $320 \pm 15$ & $44 \pm 4.3$ & $99 \pm 6.3$ & $43 \pm 3.2$ \\
\hline Main root diameter $(\mathrm{mm})$ & $1.10 \pm 0.03$ & $0.59 \pm 0.04$ & $0.81 \pm 0.04$ & $0.45 \pm 0.03$ \\
\hline Shoot dry weight $\left(\mathrm{g}\right.$ plant $\left.^{-1}\right)$ & $19.4 \pm 0.41$ & $2.4 \pm 0.07$ & $3.6 \pm 0.14$ & $1.5 \pm 0.05$ \\
\hline Root dry weight (g plant ${ }^{-1}$ ) & $2.4 \pm 0.08$ & $0.33 \pm 0.02$ & $1.24 \pm 0.04$ & $0.32 \pm 0.02$ \\
\hline Tillers (No plant $\left.{ }^{-1}\right)$ & $7.5 \pm 0.7$ & $2.1 \pm 0.3$ & $3.8 \pm 0.3$ & $1.5 \pm 0.2$ \\
\hline Ears $\left(\right.$ No plant $\left.{ }^{-1}\right)$ & $3.9 \pm 0.3$ & $1.7 \pm 0.2$ & $2.2 \pm 0.2$ & $1.5 \pm 0.2$ \\
\hline Caryopsis nitrogen content (\% D.W) & $2.07 \pm 0.02$ & $2.34 \pm 0.04$ & $1.8 \pm 0.02$ & $1.9 \pm 0.02$ \\
\hline Root nitrogen content (\% D.W) & $0.55 \pm 0.02$ & $0.63 \pm 0.06$ & $0.47 \pm 0.02$ & $0.51 \pm 0.02$ \\
\hline Straw nitrogen content ( $\%$ D.W) & $0.57 \pm 0.08$ & $0.61 \pm 0.06$ & $0.53 \pm 0.02$ & $0.57 \pm 0.02$ \\
\hline Cell number $\mathrm{cm}^{-2}\left(\begin{array}{lll}\mathrm{x} & \left.10^{9}\right)\end{array}\right.$ & $0.54 \pm 0.05$ & $0.41 \pm 0.04$ & $0.54 \pm 0.07$ & $0.45 \pm 0.03$ \\
\hline Cell number per leaf (x $\left.10^{9}\right)$ & $2.78 \pm 0.9$ & $0.98 \pm 0.3$ & $1.28 \pm 0.5$ & $0.96 \pm 0.2$ \\
\hline Cell size $\left(\mathrm{x} 10^{-9}\right)$ & $1.85 \pm 0.06$ & $2.41 \pm 0.07$ & $1.87 \pm 0.08$ & $2.24 \pm 0.04$ \\
\hline
\end{tabular}




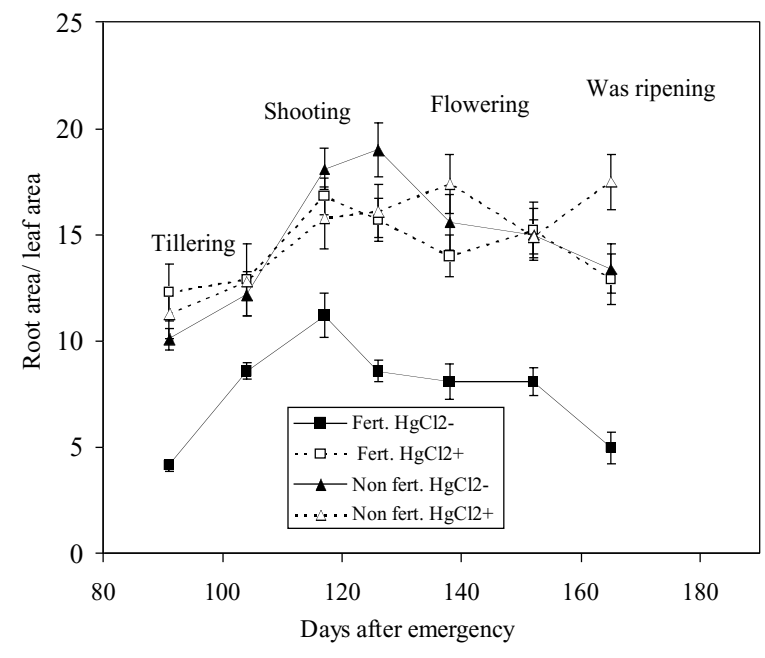

Figure 6. Mean value of root/shoot ratio on surface basis for the four theses of wheat plants during the 2005 growing cycle. Average \pm SE.

plants, then for the unfertilized and untreated plants, the smallest were measured for the unfertilized and untreated plants.

Mercuric chloride treatment and $\mathrm{N}$ deficiency induced a higher main root number per stem (Fig. 7), particularly the $\mathrm{HgCl}_{2}$ treatment. The unfertilized and treated plants showed the highest value. The lowest was found for the fertilized and untreated plants and then for the unfertilized and untreated plants. For the $\mathrm{HgCl}_{2}$ treated plants this value increased until flowering and then was constant, while for the untreated plants was always increasing.

Total root cell wall percentage (NDF) was higher for the $\mathrm{HgCl}_{2}$ treated than for untreated plants (Tab. 2). The same was observed for acid detergent fibre, which yield the lignocellulose complex, ash and some suberin part. Cellulose and emicellulose did not show any appreciable differences between $\mathrm{HgCl}_{2}$ treated and untreated plants. The ADL component, which yield lignin and some suberin part, was two folds higher in the treated plants.

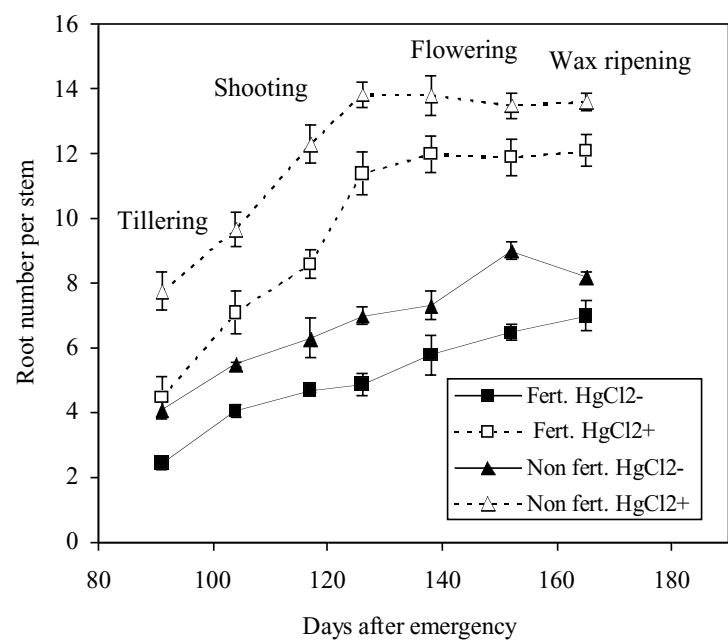

Figure 7. Mean value of root number per stem for the four theses of wheat plants during the 2005 growing cycle. Average $\pm \mathrm{SE}$.

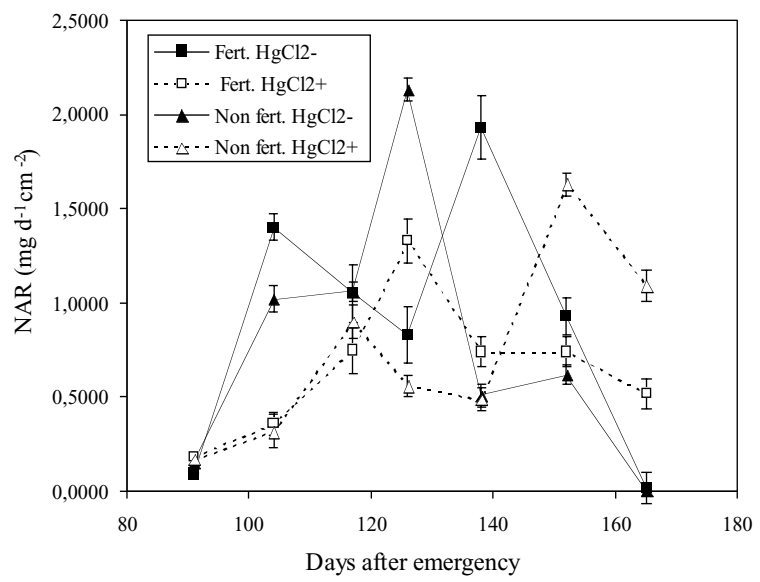

Figure 8. Mean value of NAR for the four theses of wheat plants during the 2005 growing cycle. Average \pm SE

Nitrogen deficiency and $\mathrm{HgCl}_{2}$ exposure reduced the NAR value, as average, the first of $12 \%$, the second of $28 \%$ (Fig. 8 ). These differences for nitrogen deficiency were shown principally after earing, for $\mathrm{HgCl}_{2}$ treatment mainly at the beginning of the cycle, while at the end

Table 2. Root wall cell composition for $\mathrm{HgCl}_{2}$ treated and untreated wheat plants grown in 2005 .

\begin{tabular}{lcc}
\hline & $\mathrm{HgCl}_{2}$ treated plants & $\mathrm{HgCl}_{2}$ untreated plants \\
\hline NDF (Neutral detergent fiber) \% & 74.5 & 70.06 \\
ADF (Acid detergent fiber) \% & 43.6 & 39.65 \\
Emicellulose \% & 30.9 & 30.75 \\
Cellulose \% & 31.3 & 30.83 \\
ADL (Acid detergent lignin) \% & 6.78 & 3.78 \\
\hline
\end{tabular}




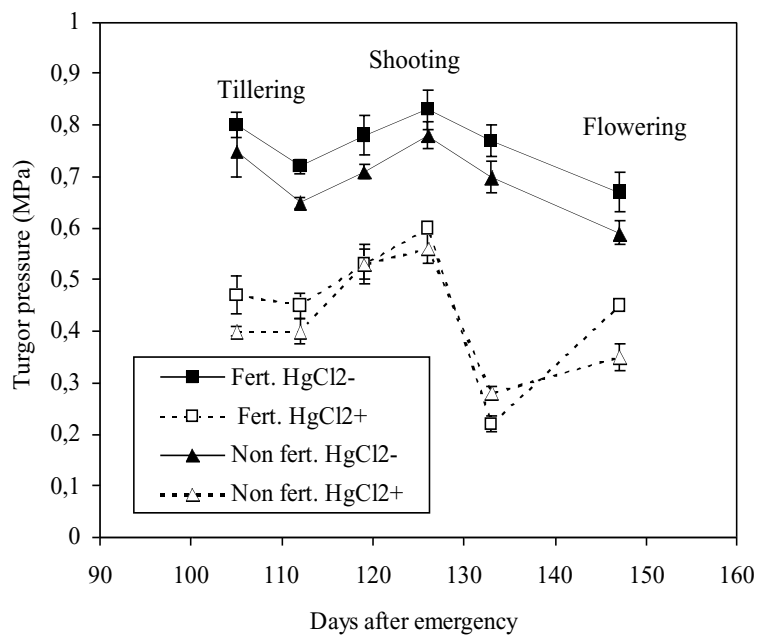

Figure 9. Mean value of leaf turgor pressure for the four theses of wheat plants during the 2005 growing cycle. Average \pm SE.

the $\mathrm{HgCl}_{2}$ exposed plants showed a NAR recovery.

Nitrogen deficiency induced only small reduction of leaf turgor pressure, which were valuable after earing (Fig. 9). For the treated plants was always registered a remarkable lower turgor pressure, without differences between fertilized and unfertilized plants. All differences were due, mainly, to total water potential variations. Osmotic water potential did not show substantial variations by $\mathrm{N}$ deficiency and $\mathrm{Hg}$ $\mathrm{Cl}_{2}$ treatment (data not reported). $\mathrm{HgCl}_{2}$ treated plants always showed leaf rolling.

The $\mathrm{HgCl}_{2}$ treatment induced a $23 \%$ reduction of the cell number per leaf area unity, while nitrogen deficiency did not change this value (Tab. 1).

As average the caryopsis nitrogen content was $2 \%$ and was higher in the fertilized plants than in the unfertilized (Tab. 1). The same was found in the root and in the straw. In the $\mathrm{Hg}$ $\mathrm{Cl}_{2}$ plants the $\mathrm{N}$ content was little higher in all parts of the plant.

\section{Discussion and conclusions}

For both species the root conductivity values are within the values reported in the literature for these two species (Rieger and Litvin, 1999), but with a high variability during growing. This variability has been, already, observed for other species and should be in relation to changes on root anatomy with ageing (Ruggiero et al., 1999, 2003; Martre et al., 2001). Rieger and Litvin (1999) observed a high correlation between root anatomy and root conductivity. It should be pointed out, also, that the barley root hydraulic conductivity resulted higher than that of wheat. This should be a species difference, but also a difference due to the different methodology used.

On both species nitrogen deprivation reduced root water conductivity. The lower effect observed for barley during the first observation should be due to soil nitrogen content, which compensated non-fertilization. At whole plant level, this is a confirmation of what is reported in literature (Radin and Ackerson, 1981; Radin and Edebock, 1984; Chapin et al., 1988; Carvajal et al., 1996; Gilbert e al., 1997; Clarkson et al., 2000; Dodd et al., 2002). Also the value of this reduction is as generally is reported on this topic.

The mercuric chloride treatment on nitrogen fertilized plants, always induced a root water conductivity reduction, and this is a further confirmation of the unfavourable effect of mercury on this parameter (Henzler and Steudle, 1995; Maggio and Joly, 1995; Carvajal et al., 1966; Kaldenhoff et al., 1998; Ranathunge et al., 2003; Wan et al., 2004; Lee and Chung 2005; LopezBerenguer et al., 2006). All these Authors agree that this is due to aquaporin blockage. However, also in these two circumstances, this effect was not observed on plant subjected to nitrogen stress. The root conductivity reduction by mercury treatment was not constant during the plant cycle. This should be due to a variation of apoplastic component, higher during the first part of the plant cycle, with younger root, or/and to temperature effect, which induced a higher aquaporin expression when temperature was higher (Lee and Chung, 2005). However, it is difficult to account the low $\mathrm{HgCl}_{2}$ effect during flowering when temperature is higher. Probably during the cycle there is a different aquaporin synthesis or expression, in relation to other factors which here are non-lightened (Vandeleur et al., 2005).

Plants subjected to $\mathrm{HgCl}_{2}$ exposition showed smaller shoot dimensions, lower tillering, lower leaf turgor pressure and leaf rolling. Also root system showed length and diameter reductions 
and more than for nitrogen deficiency. For shoot a similar behaviour was observed on rice in response to water stress (Asch et al. 2005). The $\mathrm{HgCl}_{2}$ is used as an aquaporin specific discriminator and at this dosage $(50 \mu M)$, generally, is considered not harmful on other plant functions. Nevertheless, observing the $\mathrm{HgCl}_{2}$ effect on NAR should be undertaken some negative effects on photosynthesis. However, the dimension of this effect $(-28 \%)$ justifies only small parts the growth reduction observed for the treated plants $(-89 \%)$. The lower turgor pressure should be an effect of the low root water conductivity, but, also, it should be a mercurial toxic effect (Barrowclough et al., 2000; Zang and Tyerman, 1999). With mercury exposition, on Zea mays seedlings, Rellan-Alvares et al. (2006) observed growth inibiton and oxidative stress.

Anyhow, with nitrogen deficiency and $\mathrm{HgCl}_{2}$ exposure the plant growth reduction concerned more shoot than root, with a change of root/shoot ratio. A higher root number per stem determined this result. For nitrogen deprived plants, this effect is well known (Brouwer, 1962b) and confirmed by latest researches (Mc Donald et al., 1986, Gerbin and Ruggiero, 1992, Robinson, 1994). Changes on dry matter partition favouring roots, usually, occur also with water stress (Brouwer, 1962b, Daie, 1996; Asch et al., 2005). At this regard, Chiatante et al. (1999) on pea roots observed that water stress stops the apical meristem and induces new lateral meristems. As regards the mercury effect, Kaldenhoff et al. (1998) on Arabidopsis thaliana plants, where the aquaporins expression was genetically inhibited, observed a high root growth, without changes on shoot growth. In our research, however, shoot and root growth was consistently reduced. This should be due to root conductivity reduction, to mercury toxicity or to different environmental conditions, as VPD differences (Dodd et al., 2002). However, not all the plant growth reduction is justified by measured root conductivity reduction. Probably, part of these differences are due to the toxic effect on cell multiplication, as it is observed here $(-23 \%)$, or on other functions. At the same time it should be pointed out that the treated plants experienced, also, water stress, which leads, usually, to root water conductivity reduction (Cruz et al., 1992; North and Nobel, 1995; Steudle, 2000; Martre et al., 2001; Ionenko et al.; 2004).
The wheat treated plants in the last year, probably, should be having a lower root hydraulic conductivity than those measured without continuous exposure to $\mathrm{HgCl}_{2}$. This supposition is supported by cell wall analysis. The mercury exposed plant showed more lignin than not exposed plant. Although the methodology used is not the most appropriate for this purpose (Schreiber et al., 1999), the highest lignin content shows a plant reaction to mercury treatment. Usually, the plant reacts in this way to exclude potential harmful substances, or as consequence of environmental factor as drought and salinity (North and Nobel, 1995; Reinhardt and Rost 1995; Schreiber et al., 1999, Steudle, 2000). Schreiber et al. (1999) found a 3-fold increase in endodermal suberin as reaction toward Cdstress, and a 1.5-fold increase in NaCl-and PEGtreated roots. It has been also observed an average increase of lignin by a factor of 2 .

Clarkson et al. (2000) consider the changes of root/shoot ratio as a plant compensation for the lower root conductivity, as reaction to low aquaporin synthesis or expression. As support to this hypothesis, Hong et al. (2004) showed that aquaporin RWC3 is important for drought avoidance on some rice cultivar, Ionenko et al. (2004) observed a reduction of root water conductivity as by $\mathrm{HgCl}_{2}$ treatment as by water tress and that the two effects are not additive, Martre et al. (2001), on Opuntia acanthocarpa found that roots subjected to water stress are insensitive to mercurial effect. Also our data support this hypothesis. This is justified by the unfertilized and untreated plant behaviour, with reduced root water conductivity and a high root/shoot ratio. Other factors in favouring this hypothesis are the non-mercury effects on root water conductivity for the unfertilized plants, the reduced turgor pressure for the treated plants, the higher root/shoot ratio.

In conclusions barley and durum wheat react to nitrogen deficiency and $\mathrm{HgCl}_{2}$ treatment by increasing the root/shoot ratio, to compensate water stress due to lower water root conductivity probably induced by lower aquaporin synthesis or inactivation. However, this compensation is not enough to keep a normal water status and this leads to lower plant growth. At the same time some doubts persist about mercury toxicity on other plant functions besides the aquaporin blockage. 


\section{Acknowledgements}

Thanks are due to Roberto Maiello, for his technical assistance in data acquisition and to Dr. Maria Luisa Varrichio for root cell wall analysis.

\section{References}

Asch F., Dingkuhn M., Sow A., Audebert A. 2005. Drought-induced changes in rooting patterns and assimilate partitioning between root and shoot in upland rice. Field Crops Res., 93:223-236.

Barrowclough D.E., Peterson C.A., Steudle E. 2000. Radial hydraulic conductivity along developing onion roots. J. Exp. Bot., 51:547-557.

Brouwer R. 1962b. Nutritive influences on the distribution of dry matter in the plant. Neth. J. Agric. Sci., 10, No 5 Special Issue:399-408.

Brower R. 1968. Beziehung zwischen Spross- und Würzelwachstum. Angew. Bot., 41:244-254.

Carvajal M., Cooke D.T., Clarkson D.T. 1996. Responses of wheat plants to nutrient deprivation may involve the regulation of water-channel function. Planta, 199:372-381.

Chapin F.S., Walter C.H.S., Clarkson D.T. 1988. Growth response of barley and tomato to nitrogen stress and its control by abscisic acid, water relations and photosynthesis. Planta, 173:352-366.

Chiatante D., Di Iorio A., Maturo L., Scippa S.G. 1999. Effect of water stress on root meristems in woody and herbaceous plants during the first stage of development. Plant and Soil, 217:159-172.

Clarkson D.T., Carvajal M., Henzler T., Waterhouse R.N., Smyth A.J., Cooke D.T., Steudle E. 2000. Root hydraulic conductance: diurnal aquaporin expression and the effects of nutrient stress. J. Exp. Bot., 51: 61-70.

Cruz R.T., Jordan W.R., Drew M.C. 1992. Structural changes and associated reduction of hydraulic conductance in roots of Sorghum bicolour L. following water exposure to water deficit. Plant Physiol., 99:203-212.

Daie J. 1996. Metabolic adjustment, assimilate partitioning and alterations in source-sink relations in drought-stressed plants. In: Zamiski E., Shaffer A.A. (eds.): Photoassimilation Distribution in Plants and Crops: Source-Sink Relationships. Marcel Dekker, New York-Basel-Hong Kong, 407-420.

Dodd C., Munns R., Passioura J.B. 2002. Does shoot water status limit leaf expansion of nitrogen-deprived barley? J. Exp. Bot., 53:1765-1770.

Gilbert S.M., Clarkson D.T., Cambridge M., Lambers H., Hawkesford M.J. 1997. $\mathrm{SO}^{2-}$ deprivation has an early effect on the content of ribulose-1,5-bisphosphate carboxylase/oxygenase in young leaves of wheat. Plant Physiol., 115:1231-1239.

Gherbin P., Ruggiero C. 1992. Influence of crop rotation and mineral fertilization on shoot and root growth of wheat (Triticum spp). Agr. Med., 122:262-268.

Henzler T., Steudle E. 1995. Reversible closing of water channels in Chara internodes provides evidence for a composite transport model of the plasma membrane. J. Exp. Bot., 46:199-209.

Henzler T., Waterhouse R.N., Smyth A.J., Carvajal M., Cooke D.T., Schaffner A.R., Steudle E., Clarkson D.T. 1999. Diurnal variation in hydraulic conductivity and root pressure can be correlated with the expression of putative aquaporins in the roots of Lotus japonicus. Planta, 210:50-60.

Hong-Li L., Xin Y., Quin Y., Yoshichika K., Sang-So K., Wei-Al S., Zang-Cheng T. 2004. The role of aquaporin RWC3 in drought avoidance in Rice. Plant cell physiology, 45:481-489.

Ionenko I.F, Anisimov A.V., Karimova F.G. 2006. Water transport in maize roots under the influence of mercuric chloride and water stress: a role of water channels. Biologia plantarum, 50:74-80.

Kaldenhoff R., Grote K., Zhu J-J., Zimmermann U. 1998. Significance of plasmalemma aquaporins for water transport in Arabidopsis thaliana. The Plant J., 14:121128.

Karmoker J.L., Clarkson D.T., Saker L.R., Rooney J.M., Purves J.V. 1991. Sulphate deprivation depresses the transport of nitrogen to the xylem and hydraulic conductivity of barley (Hordeum vulgare L.) roots. Planta, 185:269-278.

Lee S.H., Chung G.C. 2005. Sensitivity of root system to low temperature appears to be associated with the root hydraulic properties through aquaporin activity. Scientia Horticulturae, Vol. 105:1-11.

Lopez-Berenguer C., Garcia-Viguera C., Carvajal M. 2006. Are root hydraulic conductivity responses to salinity controlled by aquaporins in broccoli plants? Plant and Soil, 279:13-23.

Mac Donald A.J.S. 1989 Nitrate availability and shoot area development in small willow (Salix viminalis). Plant, Cell and Envirom., 7:199-206.

Maggio A., Joly R.J. 1995. Effects of mercuric chloride on the hydraulic conductivity of tomato root system. Evidence for a channels-mediated water pathway. Plant Physiol., 109:331-335.

Martre P., North G.B., Nobel P.S. 2001. Hydraulic conductance and mercury-sensitive water transport for root of Opuntia acanthocarpa in relation to soil drying and rewetting. Plant Physiol., 126:352-362.

Newmann E.I. 1966. A method of estimating the total length of root in a sample. J. Appl. Ecol., 3:139-145.

North G.B., Nobel P.S. 1995. Hydraulic conductivity of concentric root tissue of Agave deserti Engelm under wet and drying conditions. New Phytol., 130:45-57.

Radin J.W., Ackerson R.C. 1981. Water relations of cotton plants under nitrogen deficiency. III. Stomatal conductance, photosynthesis and abscisic acid accumulation during drought. Plant Physiol., 67:115-119. 
Radin J.W., Eidenbock M.P. 1984. Hydraulic conductance as a factor limiting leaf expansion in phosphorus-deficient cotton plants. Plant Physiol., 75:372-377.

Radin J.W., Matthews M.A. 1989. Water transport properties of cortical cells in roots of nitrogen and phosphorus-deficient cotton seedlings. Plant Physiol., 89:264-268.

Ranathunge K., Kotula L., Steudle E., Lafitte R. 2004. Water permeability and reflection coefficient of outer part of young rice are differently affected by closure of water channels (aquaporins) or blockage of apoplastic pores. J. Exp. Bot., 55:433-447.

Reinhardt D.H., Rost T.L. 1995. Salinity accelerates endodermal devlopment and induces an exodermis in cotton seedling roots. Env. Exp. Bot., 35:563-574.

Rieger M., Litvin P. 1999. Root system hydraulic conductivity in species with contrasting root anatomy. J. Exp. Bot., 50:201-209.

Rellan-Alvarez R., Ortega-Villasante C., Alvarez-Fernadez A., del Campo F.F., Hernadez L.E. 2006. Stress responses of zea mays to cadmium and mercury. Plant and Soil, 279:41-50.

Robinson D. 1994. Tansley Review No 73. The response of plant to non-uniform supplies of nutrients. New Physiol., 127:635-674.

Robinson D. 1996. Variation, co-ordination and compensation in root systems in relation to soil variability. In: Anderson H.M., Barlow P.W., Clarkson D.T., Jackson M.B., Shewry P.R. (eds.): Plant roots - from cell to systems, 57-66. Kluwer, Dordrecht.

Rúdinger M., Hallgren S.W., Steudle E., Shulze E.D. 1994. Hydraulic and osmotic properties of spruce roots. J. Exp. Bot., 45:1413-1425.

Ruggiero C., De Pascale S., Fagnano M. 1999. Plant and soil resistance to water flow in faba bean (Vicia faba L. major Hartz.). Plant and Soil, 210:219-231.

Ruggiero C., De Pascale S., Angelino G., Maggio A. 2003. Developmental changes in plant Resistance to water flow in Pisum Sativum. Plant and Soil, 250: 121-128.

Schulze E.D. 1982. Plant life forms and their carbon, water and nutrient relations. Encyclopaedia Plant Physiology. N.S. Vol. 12B. Springer Verlag, Berlin-Heidelberg- New York, 616-676.

Schreiber L., Hartmann K., Skrabs M., Zeier J. 1999. Apoplastic barriers in roots: chemical composition of endodermal and hypodermal cell wall. J. Exp. Bot., 50:1267-1280.

Smith F.W., Hawkesford M.J., Ealing P.M., Clarkson D.T., Vanden Berg P.J., Belcher A., Warrilow A.G.S. 1998. Regulation of expression of a cDNA from barley roots encoding a high affinity sulphate transporter. The Plant Journal, 12:875-884.

Steudle E. 2000.Water uptake by roots: effects of water deficit. J. Exp. Bot., 51:1531-1542.

Troughton A. 1977b. Relationship between the root and shoot systems of grasses. In: Marshall J.K. (ed.): The belowground ecosystem. Range Sc. Dept. Sc. Ser. $\mathrm{N}^{\circ}$ 26:39-51. Colorado State University, Fort Collins.

Troughton A. 1978. The influence of reproductive development upon the root system of perennial ryegrass and some effects upon herbage production. J. Agric. Sci., Camb., 91:427-431.

Vandeleur R., Niemietz C., Tilbrook J., Tyerman S. 2005. Roles of aquaporins in root responses to irrigation. Plant and Soil, 274:141-161.

Van Soest P.J. 1971. Newer methods of forage evaluation. N.Y. Food and Life Sci., Quart., 4:4-6.

Wan X., Steudle E., Hartung W. 2004. Gating of water channels (aquaporins) in cortical cells of young corn roots by mechanical stimuli (pressure pulse): effect of $\mathrm{ABA}$ and of $\mathrm{HgCl}_{2}$. J. Exp. Bot., 55:411-422.

Zhang W.H., Tyerman S.D. 1999. Inhibition of water channels by $\mathrm{HgCl}_{2}$ in intact wheat root cells. Plant Physiol., 120:849-858. 